\title{
Valve choice: Do data from the past misinform us as technology advances?
}

\author{
Richard J. Shemin, MD \\ From the Division of Cardiac Surgery, Department of Surgery, Cardiovascular Center at UCLA, David Geffen \\ School of Medicine at UCLA, Los Angeles, Calif. \\ Disclosures: Author has nothing to disclose with regard to commercial support. \\ Received for publication Sept 8, 2017; accepted for publication Sept 13, 2017. \\ Address for reprints: Richard J. Shemin, MD, Ronald Reagan UCLA Medical Center, David Geffen School of \\ Medicine at UCLA, 100 UCLA Medical Plaza, Suite 730, Los Angeles, CA 90095 (E-mail: Rshemin@ \\ mednet.ucla.edu). \\ J Thorac Cardiovasc Surg 2018;155:79 \\ $0022-5223 / \$ 36.00$ \\ Copyright (c) 2017 by The American Association for Thoracic Surgery \\ https://doi.org/10.1016/j.jtcvs.2017.09.061
}

The article by Schnittman and colleagues ${ }^{1}$ in this issue of the Journal, "Survival and Long-Term Outcomes After Mitral Valve Replacement in Patients Aged 18 to 50 Years," describes a propensity-matched study from patients followed up in the California and New York state databases from 1997 through 2014. Schnittman and colleagues ${ }^{1}$ found that the use of bioprosthesis valves increased, from $10 \%$ to $34 \%$, between 1997 and $2014(P<.001)$, despite the historical preference for mechanical valves for mitral valve replacement in patients younger than 50 years. The results of the study support the use of mechanical valves, because these valves afforded patients a long-term survival advantage (74.3\%; 95\% confidence interval, 69.0\%-78.7\% after bioprosthetic valve replacement vs $80.8 \%$; $95 \%$ confidence interval, $75.1 \%-85.3 \%$ after mechanical valve replacement). In addition, there was no increase in bleeding events or strokes after mechanical valve replacement relative to bioprosthetic mitral valves. The patients who received bioprosthetic valves did show increased need for reoperations (19.9\%; 95\% confidence interval, $15.4 \%-24.8 \%$ vs $5.7 \%$; $95 \%$ confidence interval, 3.5\%-8.7\%; hazard ratio, 20.3; $95 \%$ confidence interval, 4.0-102.8), which is not surprising.

These findings should have us question the trend to increased bioprosthetic valve use. If the survival benefit favors mechanical valves without increased bleeding or strokes, then these data need to be presented to patients when discussing valve choice. Postoperative anticoagulation treatment for mechanical valves has improved safety with the use of in-home international normalized ratio testing. The modification of lifestyle for these patients receiving obligate anticoagulation remains an issue that each patient must consider when deciding on a valve; however, the long-term survival benefit is perhaps the most important outcome to consider.

Shared decision making with informed consent is an important process that each surgeon must individualize with each preoperative patient encounter. Are the data from this study relevant, however? In the current era, the informed consent. prosthetic option.

\section{Reference}

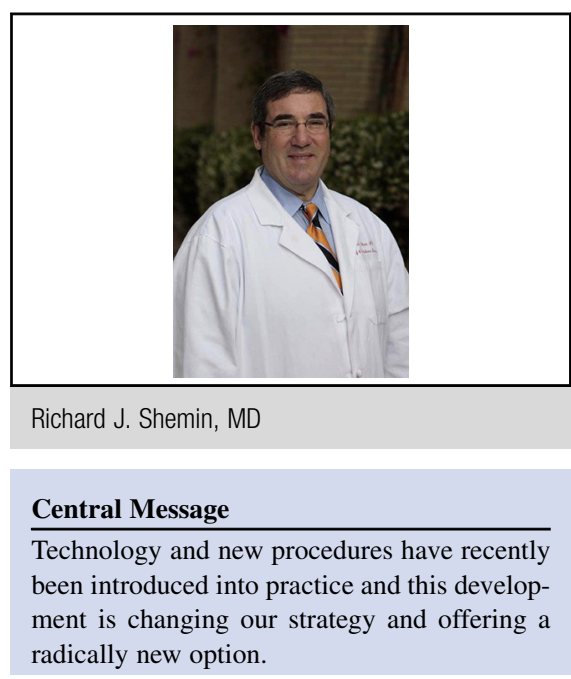

See Article page 96.

need for valve reoperation with sternotomy is reduced; the valve-in-valve strategy, approved and currently in clinical practice, with balloon expandable bioprosthetic valves, will reduce cardiopulmonary bypass and cardioplegic arrest. This strategy will clearly change the risk (procedural mortality and morbidity) of the repeat procedure. The extended period of bioprosthesis durability is not known, but the early data appear to be favorable.

The article of Schnittman and colleagues ${ }^{1}$ is an important contribution to our literature. The information is derived from the real-world practice of mitral valve replacement captured from the California and New York state databases. The information must be shared with patients during

Technology and new procedures have recently been introduced into practice and are changing our strategy by offering a radically new option. Clinical practice will not wait for the long-term data to support the valve-in-valve repeat procedure option. The pursuit of the data will ultimately inform us whether the bioprosthesis trend will improve the results from those in the current article of Schnittman and colleagues. ${ }^{1}$ The long-term survival, stroke, and bleeding rates may ultimately strongly favor the bio-

1. Schnittman SR, Itagaki S, Toyoda N, Adams DH, Egorova NN, Chikwe J. Survival and long-term outcomes after mitral valve replacement in patients aged 18 to 50 years. J Thorac Cardiovasc Surg. 2018;155:96-102.e10. 